\title{
Inhibition of Platelet Function by Recombinant Soluble Ecto-ADPase/CD39
}

\author{
Richard B. Gayle III, ${ }^{\star}$ Charles R. Maliszewski, ${ }^{*}$ Steven D. Gimpel, ${ }^{*}$ Michael A. Schoenborn, ${ }^{*}$ R. Guy Caspary, ${ }^{*}$ \\ Cheryl Richards, ${ }^{*}$ Kenneth Brasel, ${ }^{\star}$ Virginia Price, ${ }^{\star}$ Joan H.F. Drosopoulos, ${ }^{\ddagger \S}$ Naziba Islam, ${ }^{\ddagger}$ Tatiana N. Alyonycheva, ${ }^{\ddagger}$ \\ M. Johan Broekman, $\neq \S$ and Aaron J. Marcus $\$ \S \|$ \\ *Immunex Corporation, Seattle, Washington 98101; ${ }^{*}$ Division of Hematology and Medical Oncology, Department of Medicine, Veterans \\ Affairs Medical Center, New York 10010-5050; ${ }^{\S}$ Division of Hematology and Medical Oncology, Department of Medicine, and \\ Department of Pathology, Cornell University Medical College, New York 10010
}

\begin{abstract}
Excessive platelet accumulation and recruitment, leading to vessel occlusion at sites of vascular injury, present major therapeutic challenges in cardiovascular medicine. Endothelial cell CD39, an ecto-enzyme with ADPase and ATPase activities, rapidly metabolizes ATP and ADP released from activated platelets, thereby abolishing recruitment. Therefore, a soluble form of CD39, retaining nucleotidase activities, would constitute a novel antithrombotic agent. We designed a recombinant, soluble form of human CD39, and isolated it from conditioned media from transiently transfected COS-1 cells and from stably transfected Chinese hamster ovary (CHO) cells. Conditioned medium from CHO cells grown under serum-free conditions was subjected to anti-CD39 immunoaffinity column chromatography, yielding a single $\sim 66-\mathrm{kD}$ protein with ATPase and ADPase activities. Purified soluble CD39 blocked ADPinduced platelet aggregation in vitro, and inhibited collagen-induced platelet reactivity. Kinetic analyses indicated that, while soluble CD39 had a $K_{\mathrm{m}}$ for ADP of $5.9 \mu \mathrm{M}$ and for ATP of $2.1 \mu \mathrm{M}$, the specificity constant $k_{\text {cat }} / K_{\mathrm{m}}$ was the same for both substrates. Intravenously administered soluble CD39 remained active in mice for an extended period of time, with an elimination phase half-life of almost $2 \mathrm{~d}$. The data indicate that soluble CD39 is a potential therapeutic agent for inhibition of platelet-mediated thrombotic diatheses. (J. Clin. Invest. 1998. 101:1851-1859.) Key words: platelet aggregation inhibitors - CD39 antigen - adenosine diphosphate $\bullet$ recombinant proteins $\bullet$ apyrase
\end{abstract}

\section{Introduction}

Platelets adhere to sites of vascular injury, undergo activation, and subsequently release $\mathrm{ADP}$, thromboxane $\mathrm{A}_{2}$, serotonin, and several other biologically active substances. The ADP in this releasate is mainly responsible for activation, recruitment, and induction of aggregation of additional platelets in the microenvironment (1). These events constitute primary hemostasis and are followed by interactions between coagulation proteins and the activated platelet surface, culminating in

Address correspondence to Richard B. Gayle III, Immunex Corporation, 51 University Street, Seattle, WA 98101. Phone: 206-587-0430; FAX: 206-233-9733; E-mail: gayler@immunex.com

Received for publication 18 September 1997 and accepted in revised form 26 February 1998.

The Journal of Clinical Investigation

Volume 101, Number 9, May 1998, 1851-1859

http://www.jci.org thrombin generation, further platelet activation and recruitment, finally resulting in formation of an insoluble, consolidated fibrin plug (secondary hemostasis). Under normal circumstances, this hemostatic process is tightly regulated to prevent excessive clot formation and vessel occlusion. In pathologic conditions, such as a fissured atherosclerotic plaque, the normal hemostatic process can escape control by normal regulatory systems, resulting in irreversible vessel occlusion and excessive morbidity.

Vascular endothelial cells constitutively express a cell-surface ADPase (ecto-ATP diphosphohydrolase, apyrase, EC 3.6.1.5), one of at least three thromboregulatory systems which function in the maintenance of blood fluidity $(2,3)$. This ectoADPase rapidly metabolizes ADP in the platelet releasate, terminating further platelet recruitment and aggregation $(3,4)$. The enzyme belongs to the E-type ATP diphosphohydrolase (ATPDase $)^{1}$ family, members of which degrade nucleotide triand/or diphosphates, but not monophosphates (5).

In 1996, an ATPDase from potato tubers was cloned (6). The amino acid sequences of this and several other NTPases demonstrated a high degree of similarity, particularly within several small apyrase-conserved regions (ACR). CD39 $(6,7)$, a membrane-bound $95-\mathrm{kD}$ glycoprotein originally identified on activated human B lymphocytes (8-10), also contains these ACR sequences. Recently, we and others demonstrated that native and recombinant full-length CD39 possess ATPDase activity $(4,11,12)$. This was further supported by protein purification studies on ecto-ATPDases from different cell sources $(11,13)$.

Immunoprecipitation of human umbilical vein endothelial cell (HUVEC) detergent lysates with anti-CD39 mAb resulted in completex capture of cell-associated ADPase activity, suggesting that CD39 is the only ecto-ADPase on endothelial cells (4). COS cell transfectants expressing recombinant CD39 at the cell surface inhibited ADP-induced platelet aggregation (4, 11). Cells expressing CD39 reacted to oxidative stress with a loss of ATPDase activity, similar to what is seen on HUVEC (11). Thus, CD39 plays a prominent role in thromboregulation. These observations suggested that a soluble form of CD39 with full ADPase activity might constitute a novel approach to prevention and/or treatment of thromboembolic disease. In the present study we describe development of a novel recombinant, soluble form of human CD39 with potent

1. Abbreviations used in this paper: ACR, apyrase conserved regions; AG, Affigel beads; ASA, acetylsalicylic acid; ATPDase, ATP diphosphohydrolase; $\mathrm{CHO}$, Chinese hamster ovary; $\mathrm{CM}$, conditioned medium; DHFR, dihydrofolate reductase; FSBA, fluorosulfonylbenzoyladenosine; HUVEC, human umbilical vein endothelial cell; PRP, platelet-rich plasma; solCD39, recombinant soluble human CD39; TBS, Tris-buffered saline. 
ADPase and ATPase activities and strong inhibitory effects on platelet aggregation in vitro.

\section{Methods}

Reagents. The $\mathrm{B} 73 \mathrm{mAb}$, a murine $\mathrm{IgG1}$ recognizing human CD39, was kindly provided by Dr. Guy Delespesse (University of Montreal, Montreal, Canada). The M2 mAb recognizing the Flag peptide (DYKDDDDK), a murine IgG1, was prepared at Immunex Corp. Affigel 10 (Bio-Rad, Hercules, CA) and CNBr-activated Sepharose 4B (Pharmacia Biotech, Piscataway, NJ) immunoaffinity columns were prepared according to manufacturers' instructions. Typically, coupling efficiencies in the range of $3-5 \mathrm{mg} \mathrm{mAb}$ per milliliter of affinity gel slurry were obtained.

Expression plasmid construction. Using oligonucleotide cassettes and PCR primers, a CD39 sequence was constructed comprising the human coding sequence from Thr 38 to Thr 476. This removed the nucleotides coding for hydrophobic regions at the amino terminus and the carboxyl terminus (7). The remaining CD39 sequence was fused to a sequence coding for the Flag peptide and ligated into the pDC206 vector (14) with an IL-2-derived leader sequence (15), creating pIL-2L-FlagsolCD39. The pDC206 vector allows expression of recombinant protein in a variety of mammalian systems. The Flag sequence was flanked by unique restriction enzyme sites, permitting its removal to create pIL-2L-solCD39.

Preparation of conditioned medium from solCD39 transient transfectants. Plasmid DNA was transfected into subconfluent layers of COS-1 cells using DEAE dextran followed by chloroquine as previously described (16). Transfected cells were incubated $\left(37^{\circ} \mathrm{C}, 5 \%\right.$ $\mathrm{CO}_{2}$ ) in $0.5 \%$ FCS-supplemented DMEM-F12 medium in $10-\mathrm{cm}^{2}$ Petri dishes or $175-\mathrm{cm}^{2}$ tissue culture flasks. After $5 \mathrm{~d}$ (unless otherwise indicated), conditioned medium (CM) from these cultures was collected, purified of cells and debris by centrifugation, and concentrated 4-10-fold using a pressurized, stirred cell fitted with a YM-10 (10 kD cutoff) membrane (Amicon Corp., Danvers, MA).

Immunoaffinity depletion of solCD39 from COS-1 CM. CM was collected from COS-1 cells transfected with pIL-2L-FlagsolCD39, which had been cultured for $5 \mathrm{~d}$ in DMEM/F12 supplemented with $5 \%$ FCS. $100 \mu \mathrm{l}$ of drained, conjugated AG slurry was added per milliliter of CM. CM was subjected to one or two cycles of binding with one of the following: ovalbumin-conjugated AG, M2 mAb-conjugated AG, or B73 mAb-conjugated AG. Each cycle involved continuous gentle agitation of the slurry for $14 \mathrm{~h}$ at $4^{\circ} \mathrm{C}$ followed by centrifugation to recover supernatants for a subsequent binding cycle or for ATPDase activity measurements.

Development of a stably transfected cell line secreting solCD39. The solCD39 cDNA insert, containing the recombinant solCD39 sequence and the IL-2 leader, was excised from the pIL-2L-solCD39 plasmid by $\mathrm{XmaI} / \mathrm{BglII}$ digestion, then inserted into $2 \mathrm{~A} 5 \mathrm{Ib}$, an expression vector optimized for stable Chinese hamster ovary $(\mathrm{CHO})$ cell lines (17). The solCD39-2A5Ib plasmid was transfected into CHO cells using Lipofectamine (GIBCO BRL; Gaithersburg, MD) according to manufacturer's recommendations. The $\mathrm{CHO}$ cell line used in these studies, DX B-11, had been adapted to serum-free suspension culture conditions.

Transfected cells were grown in modified DMEM-F12 medium, supplemented with peptone, glutamine, glucose, transferrin, lipids, and IGF-1 (used solely when cultures were induced for protein expression). After $3 \mathrm{~d}$ growth, the cells were transferred to selective medium lacking hypoxanthine and thymidine. Stock cultures were grown at $37^{\circ} \mathrm{C}$ in suspension, and passaged every $2-3 \mathrm{~d}$. Induction cultures were grown at $31^{\circ} \mathrm{C}$ in suspension, with IGF-1 and sodium butyrate (1-2 mM). Cell density at start of induction cultures was 1.5$2.0 \times 10^{6} \mathrm{cells} / \mathrm{ml}$. Average induction culture period was $7 \mathrm{~d}$, at which time $\mathrm{CM}$ was collected for further analyses.

Radioimmunoprecipitation and SDS-PAGE autoradiography. COS-1 cells were transfected with mammalian expression vectors en- coding cell surface CD39 (pHuCD39) (4), soluble CD39 (pIL-2LFlagsolCD39), or soluble CD40 ligand (pIL-2L-CD40L) (18) and grown in $5 \%$ FCS-supplemented DMEM/F12 medium in $10-\mathrm{cm}^{2}$ dishes. $2 \mathrm{~d}$ after transfection, the medium was replaced with Cys/Metfree medium and cells were incubated for $1 \mathrm{~h}$ at $37^{\circ} \mathrm{C}$. The culture medium was replaced with fresh Cys/Met-free medium supplemented with $5 \mu$ l of [ $\left.{ }^{35} \mathrm{~S}\right]$-Cys/Met (Amersham Corp., Arlington Heights, IL), and cells were cultured for $5 \mathrm{~h}$ at $37^{\circ} \mathrm{C}$. CM from the metabolically radiolabeled cells was collected, purified of cells and debris by centrifugation and sterile filtration, and stored at $4^{\circ} \mathrm{C}$ until further use. For radioimmunoprecipitation, $500 \mu \mathrm{l}$ of ${ }^{35} \mathrm{~S}$-labeled $\mathrm{CM}$ was added to $250 \mu \mathrm{l}$ of $3 \%$ BSA in Tris-buffered saline (TBS), $\mathrm{pH} 7.7$, followed by addition of $50 \mu \mathrm{l}$ of a $80 \%$ slurry of mAb-coated AG beads. (In some cases, ${ }^{35}$ S-labeled $\mathrm{CM}$ was incubated with ovalbumin-coated AG beads to remove nonspecifically binding materials before addition of Ab-coated beads). After incubation for $14 \mathrm{~h}$ at $4^{\circ} \mathrm{C}$, beads were removed by centrifugation and washed three times in cold TBS. For SDS-PAGE analysis, $35 \mu \mathrm{l}$ of fourfold concentrated reducing sample buffer $(250 \mathrm{mM}$ Tris/HCl, $\mathrm{pH} 6.8,8 \%$ [wt/vol] SDS, $40 \%$ [vol/vol] glycerol, $20 \%$ [vol/vol] 2-mercaptoethanol, $0.05 \%$ bromophenol blue dye) was added to each AG pellet, boiled for $5 \mathrm{~min}$, and loaded onto a 8-16\% Novex (San Diego, CA) polyacrylamide gel. Gels were electrophoresed at $25 \mathrm{~mA}$ (19), prepared for autoradiography by soaking in Enhance (NEN Life Science Products, Boston, MA) for $1 \mathrm{~h}$ and in $\mathrm{H}_{2} \mathrm{O}$ for $20 \mathrm{~min}$, followed by vacuum drying at $80^{\circ} \mathrm{C}$. Gels were exposed to X-omat AR film (Eastman Kodak Co., Rochester, NY) for $2 \mathrm{~h}$, then developed.

Affinity purification of solCD39 protein. $30 \mathrm{ml}$ of 10 -fold concentrated CM from solCD39-secreting CHO cells was added to $3 \mathrm{ml}$ of B73 mAb-coated Sepharose 4B gel slurry and mixed overnight at $4^{\circ} \mathrm{C}$. The affinity matrix was pelleted by centrifugation, washed three times with PBS, and added to a plastic column. Specifically bound protein was eluted by the addition of $0.1 \mathrm{M}$ triethylamine, $\mathrm{pH} 11.5$. Fractions $(1.2 \mathrm{ml}$ each) were collected in tubes containing $120 \mu \mathrm{l}$ of neutralizing solution (1 M sodium phosphate, monobasic; $\mathrm{pH} 4.3$ ) and analyzed for protein content by SDS-PAGE, followed by Coomassie blue staining. Biological activity was determined using an ATPase assay, so that peak fractions could be pooled, buffer exchanged into PBS, and concentrated fivefold. $N$-linked sugars were removed from purified protein using $\mathrm{N}$-glycanase according to manufacturer's instructions (Oxford Glycosystems, Rosedale, NY).

Phosphate release assay for ATPase activity. Samples $(\sim 100 \mu \mathrm{l}$ of either concentrated $\mathrm{CM}$ or purified protein) were combined with $20 \mu \mathrm{l}$ of $10 \times$ assay buffer $(200 \mathrm{mM}$ Hepes, $1.2 \mathrm{M} \mathrm{NaCl}, 50 \mathrm{mM} \mathrm{KCl}$, $15 \mathrm{mM} \mathrm{CaCl}_{2}, 15 \mathrm{mM} \mathrm{MgCl}_{2}$, and $3 \mathrm{mM} \mathrm{ATP}$ ) and sterile water was added to a final volume of $200 \mu \mathrm{l}$. Radiolabeled ATP $\left(0.8 \mu \mathrm{Ci} \gamma\left[{ }^{32} \mathrm{P}\right]\right.$ ATP; Amersham Corp.) was added and the mixture incubated for 20 min at $37^{\circ} \mathrm{C}$. Stop mix $(0.5 \mathrm{ml}$ of $20 \%$ activated charcoal $/ 1 \mathrm{M} \mathrm{HCl})$ was added and the reaction was placed on ice for $10 \mathrm{~min}$. After centrifugation (14 $g$ for $10 \mathrm{~min}$ ), the supernatant was assayed for free ${ }^{32} \mathrm{P}$ using a MINAXI beta 4000 scintillation counter (Packard, Meriden, CT). Data are expressed as picomoles of ATP degraded per minute.

Radio-TLC assays for ADPase and ATPase activities. ADPase (3) assays were primarily used in determining enzyme kinetics and pharmacokinetics. Test samples were incubated with $50 \mu \mathrm{M}\left[{ }^{14} \mathrm{C}\right] \mathrm{ADP}$ (NEN Life Science Products, Boston, MA) in assay buffer (15 mM Tris, $134 \mathrm{mM} \mathrm{NaCl}, 5 \mathrm{mM}$ glucose, $\mathrm{pH}$ 7.4, containing $10 \mu \mathrm{M}$ Ap5A $\left(\mathrm{P}^{1}, \mathrm{P}^{5}\right.$-di[adenosine- $5^{\prime}$ ]pentaphosphate, $1 \mathrm{mM}$ ouabain, $10 \mu \mathrm{M}$ dipyridamole, and $\left.3 \mathrm{mM} \mathrm{CaCl}_{2}\right)$ in a total volume of $50 \mu \mathrm{l}\left(5 \mathrm{~min}, 37^{\circ} \mathrm{C}\right)$. Reactions were stopped by placement on ice and addition of $10 \mu \mathrm{l}$ "stop solution" (160 mM disodium EDTA, pH 7.0, $17 \mathrm{mM}$ ADP, $0.15 \mathrm{M} \mathrm{NaCl}$ ) to block further metabolism of ADP (3). Nucleotides, nucleosides, and bases were separated by radio-TLC using isobutanol/1-pentanol/ethylene glycol monoethyl ether $/ \mathrm{NH}_{4} \mathrm{OH} / \mathrm{H}_{2} \mathrm{O}(90$ : 60:180:90:120) (3). Radioactivity was quantified by radio-TLC scanning (RTLC multiscanner; Packard). Results were calculated as averages of duplicate to quadruplicate measurements after subtraction of buffer blanks (consistently $<1 \%$ of total radioactivity). Data were 
expressed as percentage of ADP metabolized or as picomoles ADP metabolized per min. A unit of activity is the quantity of enzyme which will degrade $1 \mu \mathrm{mol}$ of $\mathrm{ADP}$ in $1 \mathrm{~min}$ at $37^{\circ} \mathrm{C}$. Identical assays were performed using ATP as a substrate to examine the kinetics of the ATPase activity of CD39.

Preparation of platelet-rich plasma. After obtaining informed consent from volunteers, blood was collected via plastic tubing using acid citrate-dextrose ( $38 \mathrm{mM}$ citric acid; $75 \mathrm{mM}$ sodium citrate; $135 \mathrm{mM}$ glucose) as anticoagulant $(3,20)$. Where indicated, volunteers had ingested $650 \mathrm{mg}$ acetylsalicylic acid (ASA) $18 \mathrm{~h}$ before blood donation. Platelet-rich plasma (PRP) was prepared with an initial whole blood centrifugation $\left(200 \mathrm{~g}, 15 \mathrm{~min}, 25^{\circ} \mathrm{C}\right)$, and a second centrifugation of the PRP (90 g, $10 \mathrm{~min}$ ) to eliminate residual erythrocytes and leukocytes. The stock suspension of PRP was maintained at room temperature under $5 \% \mathrm{CO}_{2}$-air.

Platelet aggregation studies. PRP containing $1.22 \times 10^{8}$ platelets was preincubated $\left(3 \mathrm{~min}, 37^{\circ} \mathrm{C}\right)$ in an aggregometer cuvette (Lumiaggregometer; Chrono-Log, Havertown, PA) alone or in combination with test samples containing solCD39. Total volumes were adjusted to $300 \mu \mathrm{l}$ with TSG buffer $(3,4)$. After the 3-min preincubation, platelet agonists (ADP or collagen) were added at the concentrations indicated, and the aggregation response recorded for 4-5 $\mathrm{min}$. Where indicated, $10 \mu \mathrm{M}$ indomethacin (Sigma Chemical Co., St. Louis, MO) was added to PRP to inhibit endogenous cyclooxygenase activity.

Preparation of FSBA-modified solCD39. Fluorosulfonylbenzoyladenosine (FSBA; Sigma Chemical Co.) was used to inactivate the catalytic activity of solCD39 as follows. solCD39 (2 nmol) was combined with $2 \mathrm{ml}$ labeling buffer (100 mM Hepes, pH 7.4, $200 \mathrm{mM}$ $\mathrm{NaCl}, 4 \%$ dimethylformamide [vol/vol]), $400 \mu \mathrm{l} 5 \mathrm{mM}$ FSBA (dissolved in ethanol), and $1.52 \mathrm{ml} \mathrm{H}_{2} \mathrm{O}$. A mock-treated sample was also prepared in which the FSBA solution was replaced with $\mathrm{H}_{2} \mathrm{O}$. After incubating at $37^{\circ} \mathrm{C}$ for $90 \mathrm{~min}$, the samples were centrifuged in a Centricon-10 filter unit (Amicon Corp.) for $1 \mathrm{~h}$ at 5,500 rpm and buffer exchanged into PBS to remove unreacted material.

Biochemical analyses. Using the radio-TLC assay system as described previously (4), the ADPase activity of the membrane-bound HUVEC ecto-ADPase was determined at different $\mathrm{pHs}$ in buffers containing $100 \mathrm{mM}$ bis-trispropane (Sigma Chemical Co.). This was compared to the ADPase activity of purified solCD39 at these pHs. Kinetic constants for solCD39 metabolism of ATP and ADP were determined by measuring the initial rates of reaction as analyzed in the radio-TLC system. ADP or ATP at $2.5-150 \mu \mathrm{M}$ were incubated separately with $2 \times 10^{-9} \mathrm{M}$ solCD39.

Pharmacokinetic analysis. Balb/c mice (6-8 wk of age; maintained under specific pathogen-free conditions; Jackson Laboratory, Bar Harbor, ME) were intravenously injected with $50 \mu \mathrm{g}$ recombinant solCD39 in $100 \mu \mathrm{l}$ sterile saline $(0.9 \% \mathrm{NaCl})$. At various times after injection $(5,10,30 \mathrm{~min}, 1,2,4,8,24 \mathrm{~h})$, pairs of mice were bled by cardiac puncture and killed. Serum was prepared from each blood sample and frozen until assay. The presence of biologically active solCD39 in serum samples was measured in ATPase and ADPase assays. The data were fit using Deltagraph (Deltapoint, Monterey, CA). The best fit was derived using double exponential decay. Where indicated, specificity of enzyme activity was determined by incubating serum samples with anti-CD39 mAb-coated beads to remove solCD39 before testing for ATPase activity.

\section{Results}

Construction of a soluble CD39 (solCD39) expression plasmid. The purpose of our experiments was to generate a soluble molecule with the properties of human ADPase, which would function as an agent with antithrombotic properties. To accomplish this, it was necessary to remove the $\mathrm{NH}_{2}$-terminal and $\mathrm{COOH}$-terminal portions of CD39, including the two transmembrane regions (Fig. 1). To allow proper transport of soluble CD39 to the medium, an appropriate leader sequence

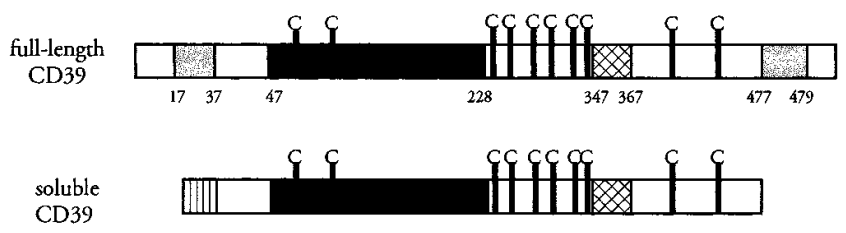

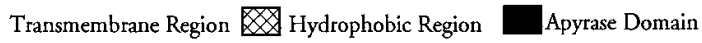
Flag and IL-2 leader

Figure 1. CD39 protein domain structure. The locations of transmembrane regions near the amino and carboxy termini (gray); the centrally located hydrophobic sequence (hatched); and a section containing the four putative apyrase conserved regions (ACR, black) (6) are indicated. Cysteine residues are marked as $\mathrm{C}$. The engineered soluble form of CD39, containing a FLAG and new leader sequence, and lacking the two transmembrane regions, is presented for comparison.

providing for secretion was required at the amino terminus of the protein. Thus, the amino terminal transmembrane region was replaced by a leader derived from human proinsulin/IL-2 sequences (15) (IL-2L) and a sequence coding for a small peptide tag, Flag. A stop codon was placed immediately upstream of the COOH-terminal transmembrane coding region (Fig. 1). This cDNA construct was ligated into the pDC206 mammalian expression plasmid, generating the pIL-2LFlagsolCD39 vector.

Production of recombinant solCD39 protein. Conditioned media (CM) from cultures of COS-1 cells transfected with pIL-2L-FlagsolCD39 were assayed for the presence of recombinant solCD39 protein. ATPase activity was detectable in CM from pIL-2L-FlagsolCD39 transfected cells, but not in CM from COS-1 cells transfected with control vector (data not shown). These ATPase levels increased with time in culture over at least $4 \mathrm{~d}$ after transfection. To confirm that recombinant solCD39 accounted for the ATPase activity observed, $\mathrm{CM}$ from COS-1 transfectants were incubated with immunoaffinity beads before enzyme assay. Immunoprecipitation with anti-CD39 mAb-conjugated beads resulted in removal of $>80 \%$ of ATPase activity from CM. Over $95 \%$ was removed with a second antibody adsorption step (Fig. 2). Immunoprecipitation (two cycles) with anti-Flag mAb-coated beads also resulted in substantial depletion of enzyme activity. Two rounds of preincubation with a control (ovalbumin-conjugated beads) did not remove significant ATPase activity from the supernatants (Fig. 2).

Immunoprecipitation of recombinant solCD39. To characterize recombinant solCD39 protein expression, COS-1 cells were transfected with pIL-2L-FlagsolCD39, grown for $2 \mathrm{~d}$, and then cultured for an additional $5 \mathrm{~h}$ in medium containing $\left[{ }^{35} \mathrm{~S}\right]-$ cysteine/methionine in order to label newly synthesized proteins. CM was collected and incubated with anti-CD39 or antiFlag mAb-coated beads. Bound proteins were analyzed by SDS-PAGE and autoradiography (Fig. 3). IL-2L-FlagsolCD39 transfectants secreted a radiolabeled protein of $\sim 66 \mathrm{kD}$ that was recognized by anti-CD39. This was not present in anti- 


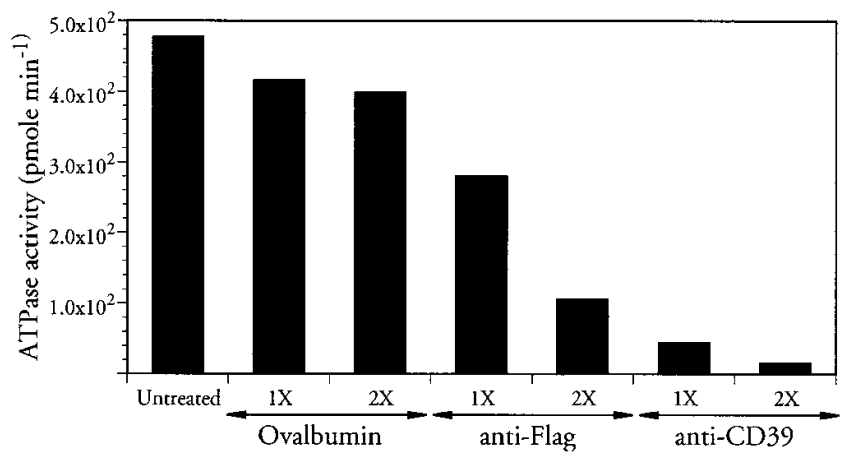

Figure 2. Identification of COS-1 CM-derived ATPase as solCD39. 5-d CM from COS-1 cells transfected with the pIL-7L-FlagsolCD39 plasmid was incubated with Affigel beads conjugated with either chicken ovalbumin, anti-Flag mAb, or anti-CD39 mAb (see Methods). Beads and $\mathrm{CM}$ were separated by low speed centrifugation. Following one $(1 X)$ or two $(2 X)$ rounds of adsorption, samples were assayed by the radioactive phosphate release assay for ATPase activity. Data are expressed as picomoles of ATP degraded per min.

CD39 immunoprecipitated CM from COS-1 cells transfected with a vector encoding full-length $\mathrm{CD} 39$ (including $\mathrm{NH}_{2}$-terminal and $\mathrm{COOH}$-terminal hydrophobic regions), or with a vector encoding a secreted protein, CD40 ligand. Anti-Flag mAb immunoprecipitated a similar-sized band from CM of the pIL2L FlagsolCD39 transfectant, consistent with the presence of the Flag peptide in recombinant solCD39 (Fig. 3). Preclearing radiolabeled culture supernatants with antiovalbumin-coated beads failed to remove the $66-\mathrm{kD}$ band, indicating that binding to anti-CD39 and anti-Flag was specific. Beads coated with an

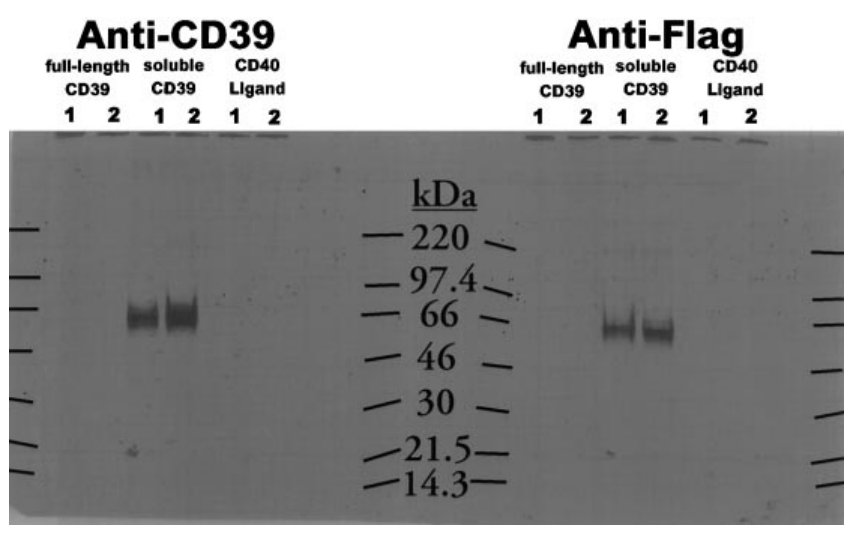

Figure 3. Immunoprecipitation of solCD39 from COS-1 CM. COS-1 cells transfected with plasmids for expression of full-length human CD39, solCD39 ( $p I L-2 L$-FlagsolCD39), or CD40 ligand ( $p I L-$

$2 L C D 40 L$ ) were metabolically labeled by culturing for $5 \mathrm{~h}$ in $\left[{ }^{35} \mathrm{~S}\right]-$ $\mathrm{Cys} /$ Met-containing medium. CM from the cultures was incubated in the presence of immunoaffinity beads coated with either anti-CD39 $\mathrm{mAb}$ or anti-Flag $\mathrm{mAb}$. Material specifically bound to the antibodycoated beads was released and subjected to SDS-PAGE and autoradiography as described in Methods (lane 2). Where indicated, some of the material was preincubated with ovalbumin-coated beads to remove nonspecifically bound material, then treated as described for lane 2 of each set (lane 1). Migration of molecular weight standards is indicated in kilodaltons.
Table I. Comparison of ADPase and ATPase Activities in CM Containing solCD39

\begin{tabular}{lcc}
\hline \multicolumn{1}{c}{ Cell type } & ADPase & ATPase \\
\hline & pmol/min/per $\mu l$ & pmol/min/per $\mu l$ \\
solCD39 (CHO) & 1403 & 970 \\
solCD39 (COS-1) & 70 & 44
\end{tabular}

Radio-TLC assays were performed on CM (see Methods). Results are expressed as pmol substrate metabolized $/ \mathrm{min} / \mu \mathrm{l} \mathrm{CM}$.

irrelevant, isotype matched control antibody failed to immunoprecipitate the $66-\mathrm{kD}$ band from solCD39 containing CM (data not shown).

Affinity purification of solCD39 from stably transfected $\mathrm{CHO}$ cells. A $\mathrm{CHO}$ cell line expressing solCD39 was generated to improve recombinant solCD39 protein production. Dihydrofolate reductase (DHFR)-deficient $\mathrm{CHO}$ cells were transfected with an expression plasmid, consisting of the 2A5Ib vector backbone, containing the DHFR gene (17), into which IL-2L-solCD39 was inserted without the Flag sequence. After growth in selective medium, $\mathrm{CM}$ from $\mathrm{CHO}$ cell cultures was analyzed for ATPase and ADPase activities. Compared to CM from transfected COS- 1 cells, the stably transfected $\mathrm{CHO}$ cells secreted 20-fold higher levels of both enzyme activities, consistent with the presence of solCD39 (Table I).

$\mathrm{CM}$ from the stably transfected $\mathrm{CHO}$ cells was affinity purified and analyzed by SDS-PAGE for the presence of recombinant solCD39 (see Methods). A prominent band of $\sim 66 \mathrm{kD}$ was present in early eluted fractions, with a peak of Coomassie Blue staining material around fraction 5 (Fig. 4 A). Over $90 \%$ of the protein present was found as this major band, although overloading the polyacrylamide gel did reveal some smaller molecular weight contaminants. ATPDase activity of the affinity column fractions correlated with the intensity of protein bands on SDS-PAGE (Fig. 4, $A$ and $B$ ). ATPDase activity was barely detectable in the anti-CD39 column flowthrough, indicating that affinity purification is an effective means of isolating biologically active recombinant solCD39. Treatment of the purified protein with $\mathrm{N}$-glycanase to remove $\mathrm{NH}_{2}$-linked oligosaccharides caused the broad band of protein at $66 \mathrm{kD}$ to resolve into a much tighter band of protein at $\sim 52 \mathrm{kD}$, the predicted peptide size for solCD39 (Fig. 4 C).

Quantitative amino acid analysis of peak fractions (3-9) from the affinity column yielded a ratio of amino acid residues consistent with calculated values for solCD39. Protein sequencing verified that the amino terminus of the isolated protein contained the CD39 sequence (data not shown). Total protein yield from 1 liter of $\mathrm{CHO}$-solCD39 $\mathrm{CM}$ was $\sim 2 \mathrm{mg}$.

Biochemical properties of affinity-purified solCD39. The $\mathrm{pH}$ optima for the ecto-ADPase on the surface of HUVEC and for affinity-purified recombinant solCD39 ADPase activities were between $\mathrm{pH} 8$ and 8.5 (Fig. $5 \mathrm{~A}$ ). This indicated that recombinant solCD39 would be maximally active under the same physiological conditions as native CD39/ecto-ADPase.

Initial rates of ATP and ADP metabolism by recombinant solCD39 were determined (Fig. $5 \mathrm{~B}$ ), and kinetic constants derived. The $K_{\mathrm{m}}$ and $V_{\max }$ for ADP were $5.9 \mu \mathrm{M}$ and $72 \mathrm{pmol} /$ min, respectively; for ATP a $K_{\mathrm{m}}$ of $2.1 \mu \mathrm{M}$ and $V_{\max }$ of 26 
A

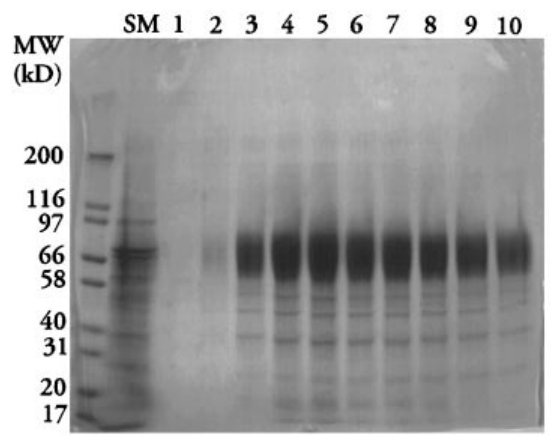

B

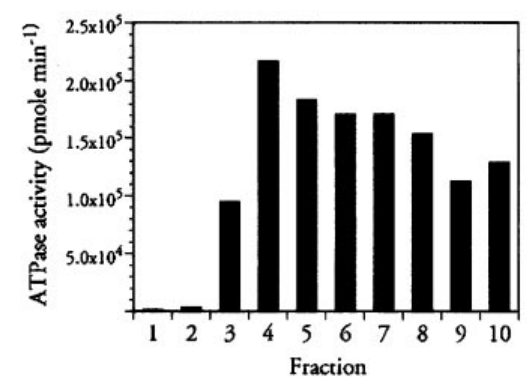

C MW

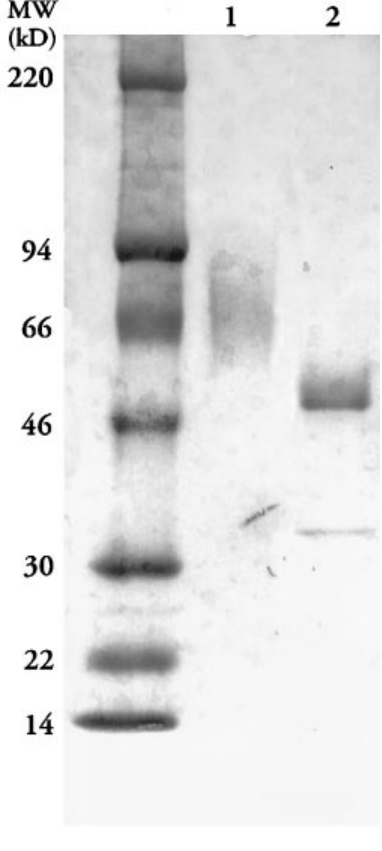

Figure 4. Immunoaffinity purification and characterization of solCD39. 5-d CM from CHO cells stably transfected with the solCD39 expression plasmid was concentrated and incubated overnight with antiCD39 immunoaffinity beads. After extensive washing, specifically bound protein was eluted from the beads with triethanolamine, $\mathrm{pH} 11.5$ and immediately neutralized in $1 \mathrm{M}$ sodium phosphate, monobasic; $\mathrm{pH}$ 4.3. Fractions from the immunoaffinity column were analyzed for $(A)$ protein content by SDS-PAGE, and $(B)$ enzyme activity by the radioactive phosphate release assay (see Methods). (C) Purified solCD39 (lane 1 ) was treated with $N$-glycanase (see Methods) for $18 \mathrm{~h}$ (lane 2). The protein band at $\sim 35 \mathrm{kD}$ in lane 2 corresponds to the $N$-glycanase used in the reaction.

A

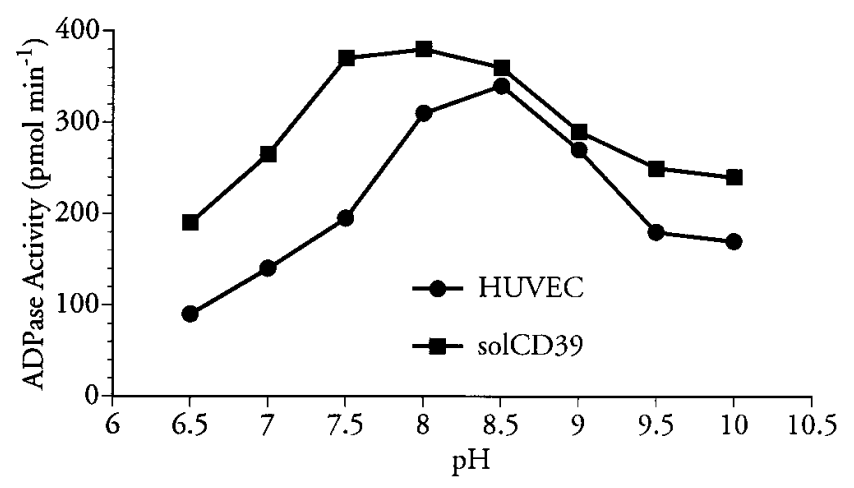

B

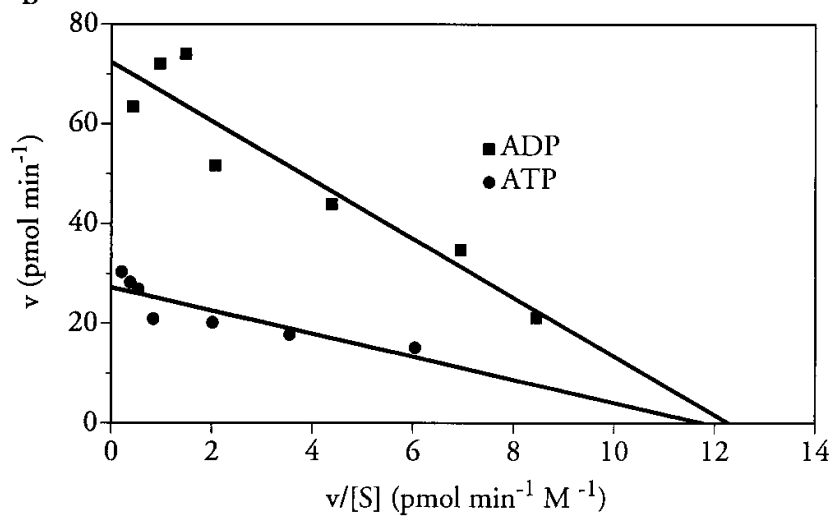

Figure 5. Biochemical characteristics of solCD39. (A) pH optimum profiles of HUVEC membrane ecto-ADPase and recombinant solCD39. HUVEC membrane ecto-ADPase (4) and purified solCD39 from $\mathrm{CHO}$ cell $\mathrm{CM}$ were assayed for ADPase activity in bistris propane buffer at the indicated $\mathrm{pH}$ (see Methods). (B) EadieHofstee plot of rates of metabolism at different concentrations of ATP or ADP using purified solCD39 (6.5 ng). Increasing quantities of substrates were reacted with solCD39, and ADPase activity measured by radio-TLC (see Methods). $\mathrm{pmol} / \mathrm{min}$ were determined. The assays were performed with $2 \times 10^{-9} \mathrm{M}$ solCD39, yielding $k_{\text {cat }}$ of $720 \mathrm{~min}^{-1}$ (ADP) and $260 \mathrm{~min}^{-1}$ (ATP). Thus, the specificity constant $k_{\text {cat }} / K_{\mathrm{m}}$ $\left(1.2 \times 10^{8} \mathrm{~min}^{-1} \mathrm{M}^{-1}\right)$ was identical for ADP and ATP. The specific activity for purified recombinant solCD39 was $11 \mathrm{U} / \mathrm{mg}$ for ADP and $4 \mathrm{U} / \mathrm{mg}$ for ATP.

Platelet inhibitory properties of solCD39. The aforementioned biochemical properties of recombinant affinity purified solCD39 suggested that it might be effective as an inhibitor of platelet reactivity. As shown in Fig. 6, this was indeed the case. Whereas addition of $10 \mu \mathrm{M}$ ADP to PRP alone resulted in a
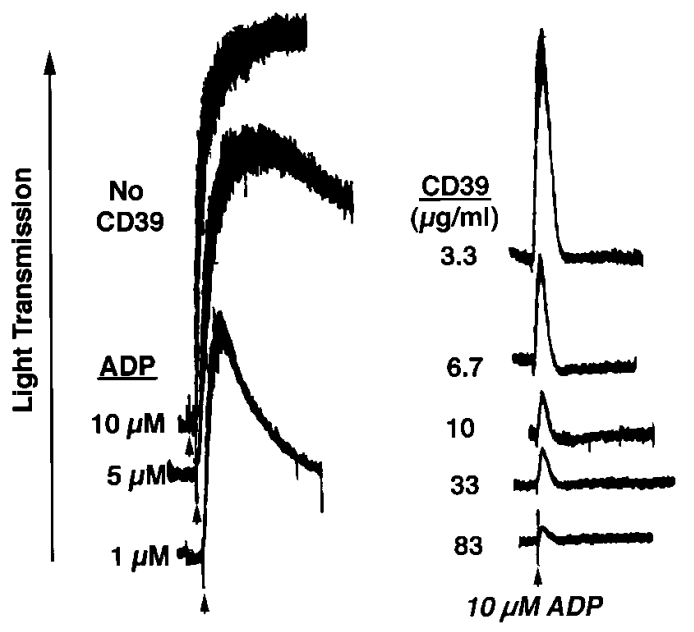

Figure 6. Inhibition of ADP-induced platelet reactivity by purified solCD39. Platelet aggregation in PRP from a donor who had ingested aspirin was studied. The response to increasing concentrations of ADP is shown on the left. The effect of increasing quantities of purified solCD39 on the platelet aggregation response to $10 \mu \mathrm{M}$ ADP is shown on the right. Arrows indicate addition of agonist. Data are presented as relative light transmission vs time (4-min duration). 
full, irreversible aggregation response, partially reversible aggregation occurred at lower ADP concentrations. However, in the presence of only $3.3 \mu \mathrm{g} / \mathrm{ml}$ solCD 39 , platelet aggregation induced by $10 \mu \mathrm{M}$ ADP was abruptly terminated and the curve rapidly returned to baseline (Fig. 6). Importantly, the extent of aggregation was reduced to levels below those observed with $1 \mu \mathrm{M}$ ADP. Higher concentrations of solCD39 had an even more profound inhibitory effect, virtually eliminating the initial burst of aggregation elicited by $10 \mu \mathrm{M}$ ADP. Thus, these results indicate that purified solCD39 is indeed an effective inhibitor of platelet aggregation in vitro.

Platelet responsiveness to $5 \mu \mathrm{M}$ ADP was examined in PRP treated with and without the cyclooxygenase inhibitor indomethacin $(10 \mu \mathrm{M})$, in the presence of $\mathrm{CM}$ containing solCD39 from either COS-1 and CHO cells (Fig. $7 A$ ). Indomethacin treatment resulted in partial reversal of ADPinduced platelet aggregation in the absence of solCD39. In contrast, CM containing solCD39 were capable of completely abrogating platelet responses to ADP, whether PRP was indomethacin treated or not.

A

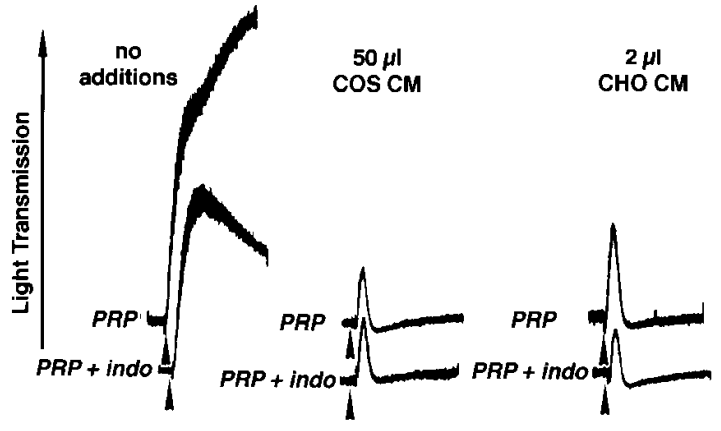

B

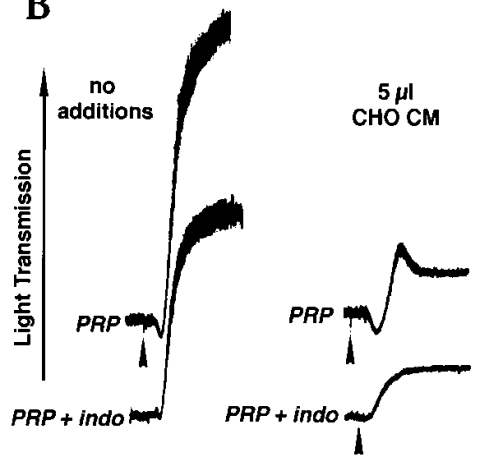

C

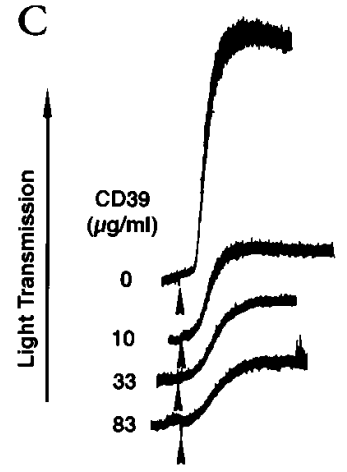

Figure 7. Comparison of platelet reactivity as modulated by different agonists and inhibitors. The effects of CM from COS- 1 or $\mathrm{CHO}$ cells expressing solCD39 on platelet aggregation induced by $(A) \operatorname{ADP}(5 \mu \mathrm{M})$ and $(B)$ collagen were compared in PRP, and PRP treated with $10 \mu \mathrm{M}$ indomethacin (a cyclooxygenase inhibitor). In $B, 1 \mu \mathrm{g} / \mathrm{ml}$ collagen was used in the upper samples, and $3.3 \mu \mathrm{g} / \mathrm{ml}$ in the lower (indomethacin-treated) samples. $(C)$ The inhibition of collagen-induced aggregation by increasing quantities of solCD39 in PRP from a donor who had ingested aspirin. Arrows indicate addition of agonist. Data are presented as relative light transmission vs time (4 min).
A
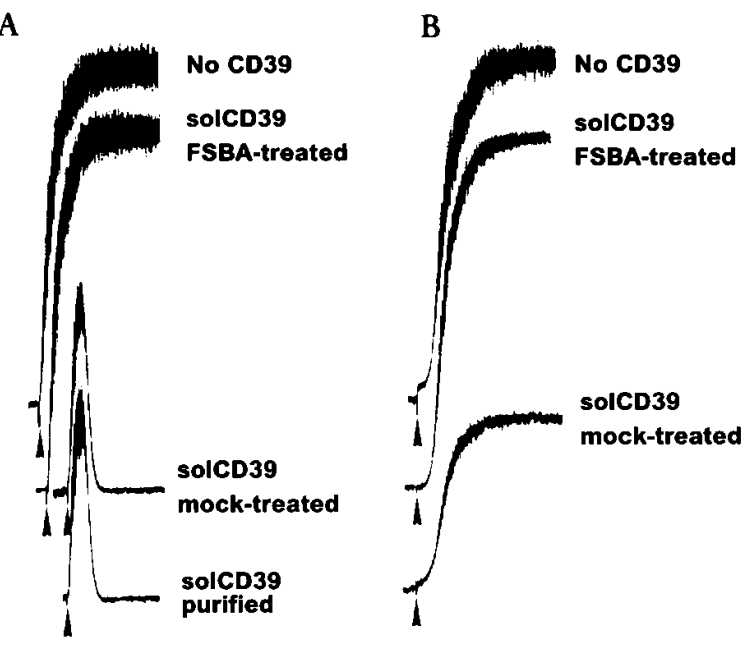

$\mathrm{C}$

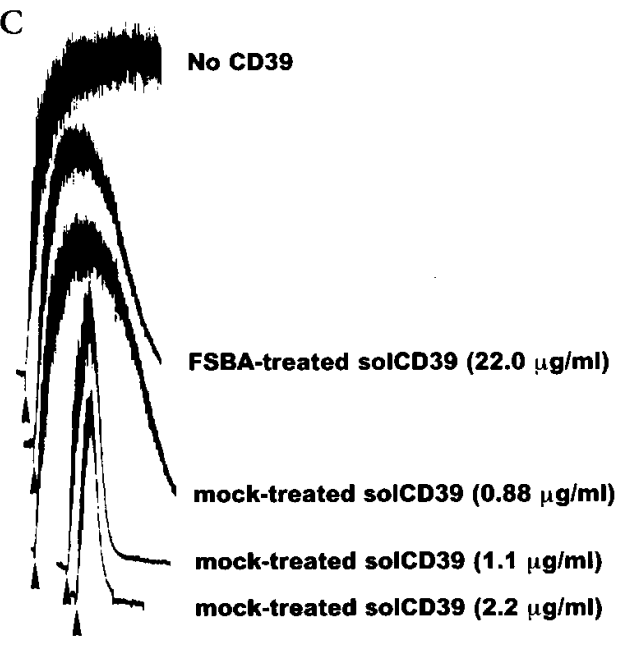

Figure 8. Examination of the effect of FSBA-treated solCD39 on platelet reactivity. FSBA-treated solCD39 and mock-treated solCD39 were generated as described in Methods. $(A)$ The effects of purified solCD39, FSBA-treated solCD39 and mock-treated solCD39 (each at $4.4 \mu \mathrm{g} / \mathrm{ml}$ ) on ASA-treated PRP after addition of $10 \mu \mathrm{M}$ ADP. (B) The effects of FSBA-treated solCD39 and mock-treated solCD39 (each at $22 \mu \mathrm{g} / \mathrm{ml}$ ) on ASA-treated PRP following addition of $3.3 \mu \mathrm{g} / \mathrm{ml}$ collagen. $(C)$ Titration of mock-treated solCD39 $(0.88$ $2.2 \mu \mathrm{g} / \mathrm{ml})$ against FSBA-treated solCD39 $(22 \mu \mathrm{g} / \mathrm{ml})$. ASA-treated PRP was stimulated with $10 \mu \mathrm{M}$ ADP. Arrows indicate addition of agonist. Data are presented as relative light transmission vs time.

Inhibition of platelet reactivity by solCD39 was not limited to blocking the agonistic effects of ADP. Collagen, another critical platelet agonist, was used at $1 \mu \mathrm{g} / \mathrm{ml}$ to induce platelet aggregation. The presence of solCD39 markedly reduced the response to collagen as compared to control (Fig. $7 \mathrm{~B}$, upper curves). A similar inhibitory effect of solCD39 was observed in PRP treated with indomethacin (Fig. $7 \mathrm{~B}$, lower curves), when collagen was used at $3.3 \mu \mathrm{g} / \mathrm{ml}$. The effect of solCD39 on collagen-induced aggregation was dose dependent (Fig. $7 \mathrm{C}$ ).

Inactivation of enzymatic activity of solCD39 and the effect on inhibition of platelet activation. To demonstrate that the ability of solCD39 to inhibit platelet activation was due to the enzymatic activity of solCD39 and not to some other property, 
the molecule was reacted with FSBA, an ATP analogue that inhibits collagen-induced platelet activation (21) and binds irreversibly with ATPDases found on several cell types $(22,23)$. Induction of platelet activation by ADP (Fig. $8 A$ ) or collagen (Fig. 8 B) was significantly inhibited by either purified solCD39 or mock FSBA-treated solCD39. In contrast, incubation with FSBA-treated solCD39 did not have a significant effect on platelet activation. A comparative titration of mocktreated solCD39 versus FSBA-treated solCD39 (Fig. 8C) indicated that $22.0 \mu \mathrm{g} / \mathrm{ml}$ of FSBA-treated solCD39 gave a similar aggregation profile as $0.88 \mu \mathrm{g} / \mathrm{ml}$ of mock-treated solCD39. This indicated that $96 \%$ of the aggregation inhibitory activity of solCD39 was lost after FSBA derivitization. Analyses of residual ADPase activity of FSBA-treated solCD39 by the radio-TLC assay system demonstrated that $\sim 94 \%$ of the enzymatic activity was blocked, while the phosphate release assay indicated that a similar percentage of the ATPase activity was lost as well (data not shown).

Persistence of solCD39 after in vivo administration. Mice were injected with solCD39 $(50 \mu \mathrm{g})$ intravenously and bled at specified time intervals thereafter. Serum samples were examined for both ATPase and ADPase activities. The data obtained best fit a biphasic exponential curve. The amount of ATPase activity from $25 \mu \mathrm{g} / \mathrm{ml}$ of solCD39 placed in murine serum is presented for comparison. The $t_{1 / 2} \alpha$ (distribution phase) was calculated to be $59 \mathrm{~min}$ in the ATPase assay and 43 min in the ADPase assay (Fig. 9). Approximately 55-65\% of apyrase activity was cleared from the circulation during this

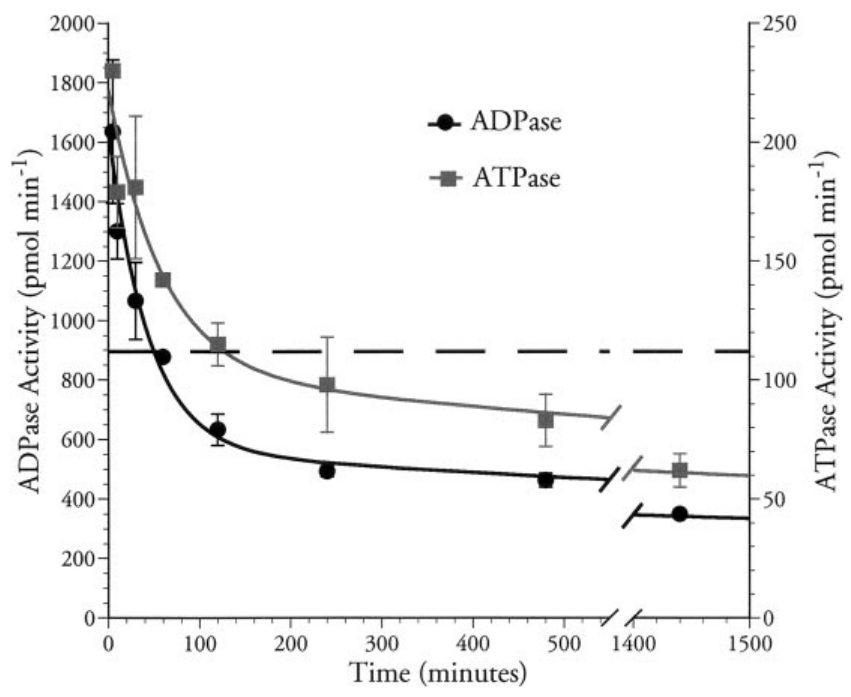

Figure 9. Pharmacokinetic analysis of solCD39 in mice. SolCD39 (50 $\mu \mathrm{g}$ in $100 \mu \mathrm{l}$ sterile saline) was injected intravenously into Balb/c mice. At various time points ( $5 \mathrm{~min}$ to $24 \mathrm{~h}$ after injection), mice were bled by cardiac puncture and serum was prepared. ATPDase in serum was measured in the radioactive phosphate release ATPase assay (ם) or the ADPase assay (@) (see Methods). Both activities are expressed as picomoles nucleotide degraded per minute. The dashed line, which indicates the ATPase activity of $25 \mu \mathrm{g} / \mathrm{ml}$ of solCD39 in murine serum, is provided as a comparison. The data were fit to a biphasic curve (see Methods) resulting in $\sim 65 \%$ of the activity being present in the distribution phase $\left(t_{1 / 2} \alpha=59 \mathrm{~min}[A T P] ; 43 \mathrm{~min}\right.$ $[A D P])$ and the remaining $35 \%$ being present in the elimination phase $\left(t_{1 / 2} \beta=40 \mathrm{~h}[A T P \& A D P]\right)$. phase. The elimination phase had a $t_{1 / 2} \beta$ of $\sim 40 \mathrm{~h}$ in both assays. Preclearing the $10 \mathrm{~min}, 2$, and $24 \mathrm{~h}$ time point samples with anti-CD39 mAb-coated beads completely eliminated serum ATPase/ADPase activities (data not shown). These data also demonstrated that the assays specifically detected recombinant human solCD39.

\section{Discussion}

Excessive platelet activation is a contributing factor to several clinical disorders, including myocardial infarction, restenosis after angioplasty or bypass surgery, and stroke. Thus, it follows that therapeutic strategies wherein platelet reactivity is pharmacologically neutralized $(24,25)$ would be clinically beneficial. This creates an impetus to expand development of potential therapeutic agents which show promise in vitro. In vitro studies demonstrated that ADP secreted from stimulated platelets is rapidly metabolized by endothelial ecto-ADPase/ CD39, and thereby becomes unavailable for promotion of further platelet activation and recruitment $(3,4,11)$. This indicated that CD39 might be useful as an antithrombotic agent. For in vivo evaluation of ecto-ADPase/CD39, a recombinant soluble form was deemed necessary. Research presented in this paper describes a novel soluble, recombinant ADPase/ CD39, solCD39, which is capable of returning stimulated platelets to the resting state, confirming its potential as an antithrombotic agent.

CD39 contains two putative transmembrane regions, near the amino and carboxyl termini, respectively, which may serve to anchor the native protein in the cell membrane (Fig. 1) (7). Modeling studies, antibody epitope analyses, and sequence homology have shown that the portion of the molecule between the transmembrane regions is external to the cell (7), and contains the four ACRs characteristic of members of the apyrase family $(6,7)$. This suggested that the external portion of CD39 is critical for its ecto-ADPase activity. The extracellular domain, which encodes a 439 amino acid polypeptide, was isolated using oligonucleotide cassettes and PCR and placed in a mammalian expression vector. Secretion of the recombinant molecule was ensured by addition of a mammalian leader sequence. After transfection with solCD39-encoding plasmid, COS- 1 cells secreted readily detectable levels of ATPase activity (Fig. 2). This activity was solCD39 specific, since: (a) cells transfected with unrelated plasmids failed to secrete nucleotidase activity, and (b) solCD39 CM was depleted of apyrase activity by specific immunoadsorption (Fig. 3). The molecular size of solCD39 immunoprecipitated from COS-1 CM $(\sim 66 \mathrm{kD}$, Fig. $4 C$ ) was larger than the predicted size of $52 \mathrm{kD}$. However, incubation of the purified protein with $N$-glycanase to remove $N$-linked oligosaccharides yielded protein with the appropriate molecular weight.

To increase protein production, a modified CHO-based solCD39 expression system was used. This could be maintained as a stably expressing line, and could also be grown in a defined, serum-free medium to facilitate protein purification. $\mathrm{CM}$ from these $\mathrm{CHO}$ cells contained 20-fold more ATPase and ADPase activity than that from COS cells (Table I). Affinity purification (see Methods) resulted in yields of 1-3 mg solCD39/liter CM, which remained biologically active upon extended storage at $4^{\circ} \mathrm{C}$ (data not shown).

The $\mathrm{pH}$ optimum of solCD39 ADPase activity was be- 
tween 8 and 8.5, similar to that of HUVEC membrane-bound ecto-ADPase (4), and other reported ATPDases (13, 26). The specific activities of solCD39 (4 U/mg for ATP and $11 \mathrm{U} / \mathrm{mg}$ for ADP) are of the same order as those seen for other mammalian ecto-apyrases $(13,27)$. Care must be taken when comparing these values, however, as there are many conditions used in the purification process that could affect the specific activity of solCD39. In fact, recent modifications in the purification protocols have increased the specific activity two- to fivefold (data not shown).

It is important to examine the kinetic constants for solCD39 in some detail. The $K_{\mathrm{m}}$ reveals the concentration of substrate at which the enzymatic degradation delineated by $k_{\text {cat }}$ is most efficient. The $K_{\mathrm{m}}$ of solCD39 for its substrates $(5.9 \mu \mathrm{M}$ for ADP, $2.1 \mu \mathrm{M}$ for ATP) is quite low, similar to that of other mammalian ecto-ATPDases. For example, an ATPDase from bovine lung had a $K_{\mathrm{m}}$ for ATP of $7 \mu \mathrm{M}$ (28), and an ATPDase from bovine spleen had a $K_{\mathrm{m}}$ for ADP of $9 \mu \mathrm{M}$ (26). A recently reported ATPDase, purified from bovine heart and having antigenic similarities to CD39, has been found to have a $K_{\mathrm{m}}$ for ADP of $29 \mu \mathrm{M}$ (27). Importantly, the $K_{\mathrm{m}}$ for ADP of solCD39 is in the range at which ADP exerts its biological activity on platelets, as ADP and ATP concentrations present in serum after platelet activation are 3-5 $\mu \mathrm{M}(29,30)$. Thus solCD39 should degrade ATP and ADP very efficiently at biologically relevant concentrations of these nucleotides, with virtually every molecule of solCD39 participating in the reaction. The potato apyrase, which has a higher $k_{\text {cat }}$ than solCD39 for ATP, also has a significantly higher $K_{\mathrm{m}}$, thus resulting in a $k_{\text {cat }} /$ $K_{\mathrm{m}}$ with a similar magnitude as solCD39 (6). Potato apyrase, while capable of degrading bound nucleotide faster than solCD39, will, at biologically relevant concentrations, have far fewer protein molecules participating in the reaction. The similarities in $k_{\text {cat }} / K_{\mathrm{m}}$ for both solCD39 and potato apyrase suggest that, at the low concentrations of extracellular ADP observed after platelet activation, equal concentrations of solCD39 and potato apyrase will have comparable rates of nucleotide degradation.

Examination of the specificity constants $\left(k_{\text {cat }} / K_{\mathrm{m}}\right)$ of solCD39 for the two substrates shows no preference for one over the other. As a consequence, when ATP and ADP are both present, the ratio of degradation rates $\left(\nu_{\mathrm{ADP}} / \nu_{\mathrm{ATP}}\right)$ will always equal the ratio of substrate concentrations ([ADP]/ [ATP]). This may have important implications not only for thrombosis, but for other settings as well. For example, CD39 is expressed on alloactivated cytotoxic T lymphocytes (CTL) (31), and an ecto-ATPase activity on CTL is required for effector functions (32). Inhibition of ATPase activity blocks secretion of relevant cytokines, such as TNF- $\alpha$ and IFN- $\gamma$, as well as cell-mediated killing. Incubation of PMN with ATP and ADP inhibits the biological activities of these cells (33). Interestingly, this inhibition is due to accumulation of AMP. Investigations that the role of CD39 plays in this and other immunologically relevant processes may yield valuable insights.

Significant quantities of recombinant solCD39 can now be prepared in order to investigate details of its biological activity in vitro and in vivo. As depicted in Figs. 6-8, solCD39 strongly inhibits platelet aggregation and recruitment in an aggregometry system, an in vitro model of thrombosis. In the absence of solCD39, addition of ADP or collagen to PRP results in rapid, irreversible aggregation (Figs. 6 and 7). Results with collagen are of particular interest. This strong platelet agonist promotes platelet aggregation via pathways independent of release of ADP and other dense body constituents from platelets (34). As seen in Fig. 7, $B$ and $C$, solCD39 inhibition of collageninduced platelet aggregation was very pronounced. This could indicate that ADP contributes more to collagen-induced aggregation than previously appreciated $(35,36)$.

Our data indicate that solCD39 leads to more effective blockade of platelet responsiveness than cyclooxygenase inhibition (Fig. 7, $A$ and $B$ ). Cyclooxygenase inhibitors, such as aspirin or indomethacin, reduced the extent of platelet aggregation, but disaggregation did not occur, even over a period of several minutes. In contrast, solCD39 significantly decreased platelet aggregation to collagen (Fig. $7 \mathrm{~B}$ ), and completely inhibited the platelet response to $10 \mu \mathrm{M}$ ADP (Fig. $7 A$ ). Inhibition of platelet reactivity by solCD39 is independent of cyclooxygenase inactivation. This indicates that aspirin and solCD39 could be utilized concurrently as therapeutic modalities.

To verify that the inhibition of collagen-induced platelet activation by solCD39 was due to its enzymatic activity and not due to another aspect of the molecule (e.g., binding to reactive sites on collagen or on platelets), solCD39 was reacted with a substrate analogue, FSBA. This molecule binds near the active site and prevents further catalysis (37). After treatment, the molecule could no longer metabolize ADP efficiently, having lost $94 \%$ of its activity. The loss in catalytic activity paralleled the inability of the material to inhibit platelet activation after addition of ADP or collagen (Fig. 8). Mock-treated solCD39 continued to inhibit platelet reactivity. Therefore, the ability of solCD39 to inhibit platelet aggregation is due solely to its enzymatic activity.

In vivo analyses in mice demonstrated that intravenously administered solCD39 remained active in the circulation for extended periods of time and was not inactivated during serum preparation (Fig. 9). Two different assays, examining both ATPase and ADPase activities of solCD39, produced very similar results. The initial reduction in solCD39 activity (distribution phase) was followed by a considerably slower clearance phase. A comparison between the ATPase activity of a known amount of solCD39 placed into murine serum (Fig. 9, dashed line) with the activity seen in intravenously administered solCD39, coupled with the half-life of almost $2 \mathrm{~d}$ seen during the clearance phase, indicates that potentially therapeutic levels of solCD39 may be sustainable for long periods. This would obviate the need for complicated administration protocols such as continuous infusion. Furthermore, it is noteworthy that mice treated with $50 \mu \mathrm{g}$ of solCD39 displayed no overt external difficulties over the observation period. Experiments are currently under way to examine the biological effects of solCD39 in relevant animal models of vascular diseases.

In summary, data obtained with a novel, soluble form of recombinant human ecto-ADPase, solCD39, indicates potential for a new class of antithrombotic agents. solCD39 blocks and reverses platelet activation, preventing recruitment of additional platelets into a growing thrombus. In this manner, the extent of occlusion as well as vascular wall damage during and immediately after cardio- and cerebrovascular events such as stroke, myocardial infarction, angioplasty, and stenting might be largely prevented. Importantly, because of its independent mode of action, solCD39 could be combined with currently utilized therapeutic agents, including heparin, aspirin, and GP IIb/IIIa antagonists. 


\section{Acknowledgments}

The authors wish to thank Norman Boiani for technical support; Drs. Doug Williams, Carl March, and Ray Paxton for critical review of the manuscript; and Christine Jones for editorial assistance.

This work was supported in part by a Merit Review grant from the Department of Veterans Affairs and by National Institutes of Health grants HL-47073, HL-46403, and HL-07423.

\section{References}

1. Marcus, A.J. 1996. Platelets and their disorders. In Disorders of Hemostasis. O.D. Ratnoff and C.D. Forbes, editors. W.B. Saunders, Philadelphia. 79137.

2. Marcus, A.J., and L.B. Safier. 1993. Thromboregulation: multicellular modulation of platelet reactivity in hemostasis and thrombosis. FASEB J. 7: 516-522.

3. Marcus, A.J., L.B. Safier, K.A. Hajjar, H.L. Ullman, N. Islam, M.J. Broekman, and A.M. Eiroa. 1991. Inhibition of platelet function by an aspirininsensitive endothelial cell ADPase. Thromboregulation by endothelial cells. $J$. Clin. Invest. 88:1690-1696.

4. Marcus, A.J., M.J. Broekman, J.H.F. Drosopoulos, N. Islam, T.N. Alyonycheva, L.B. Safier, K.A. Hajjar, D.N. Posnett, M.A. Schoenborn, K.A. Schooley, R.B. Gayle, III, and C.R. Maliszewski. 1997. The endothelial cell ecto-ADPase responsible for inhibition of platelet function is CD39. J. Clin. Invest. 99:1351-1360.

5. Plesner, L. 1995. Ecto-ATPases: identities and functions. Int. Rev. Cytol. 158:141-214

6. Handa, M., and G. Guidotti. 1996. Purification and cloning of a soluble ATP-diphosphohydrolase (apyrase) from potato tubers (Solanum tuberosum). Biochem. Biophys. Res. Commun. 218:916-923.

7. Maliszewski, C.R., G.J. Delespesse, M.A. Schoenborn, R.J. Armitage, W.C. Fanslow, T. Nakajima, E. Baker, G.R. Sutherland, K. Poindexter, C. Birks, et al. 1994. The CD39 lymphoid cell activation antigen. Molecular cloning and structural characterization. J. Immunol. 153:3574-3583.

8. Rowe, M., J.E. Hildreth, A.B. Rickinson, and M.A. Epstein. 1982. Monoclonal antibodies to Epstein-Barr virus-induced, transformation-associated cell surface antigens: binding patterns and effect upon virus-specific T-cell cytotoxicity. Int. J. Cancer. 29:373-381.

9. Ling, N.R., D. Hardie, J. Lowe, G.D. Johnson, M. Khan, and I.C. MacLennan. 1989. A phenotypic study of cells from Burkitt lymphoma and EBVB-lymphoblastoid lines and their relationship to cells in normal lymphoid tissues. Int. J. Cancer. 43:112-118.

10. Kansas, G.S., G.S. Wood, and T.F. Tedder. 1991. Expression, distribution, and biochemistry of human CD39. Role in activation-associated homotypic adhesion of lymphocytes. J. Immunol. 146:2235-2244.

11. Kaczmarek, E., K. Koziak, J. Sévigny, J.B. Siegel, J. Anrather, A.R. Beaudoin, F.H. Bach, and S.C. Robson. 1996. Identification and characterization of CD39 vascular ATP diphosphohydrolase. J. Biol. Chem. 271:3311633122 .

12. Wang, T.F., and G. Guidotti. 1996. CD39 is an ecto- $\left(\mathrm{Ca}^{2+}, \mathrm{Mg}^{2+}\right)$-apyrase. J. Biol. Chem. 271:9898-9901.

13. Christoforidis, S., T. Papamarcaki, D. Galaris, R. Kellner, and O. Tsolas. 1995. Purification and properties of human placental ATP diphosphohydrolase. Eur. J. Biochem. 234:66-74.

14. Kozlosky, C.J., E. Maraskovsky, J.T. McGrew, T. VandenBos, M. Teepe, S.D. Lyman, S. Srinivasan, F.A. Fletcher, R.B. Gayle, III, and D.P. Cerretti. 1995. Ligands for the receptor tyrosine kinases hek and elk: isolation of cDNAs encoding a family of proteins. Oncogene. 10:299-306.

15. Cullen, B.R. 1988. Expression of a cloned human interleukin-2 cDNA is enhanced by the substitution of a heterologous mRNA leader region. DNA (NY). 7:645-650.

16. Cosman, D., D.P. Cerretti, A. Larsen, L. Park, C. March, S. Dower, S. Gillis, and D. Urdal. 1984. Cloning, sequence and expression of human interleukin-2 receptor. Nature. 312:768-771.
17. Morris, A.E., C. Lee, K. Hodges, T.L. Aldrich, C. Krantz, P.S. Smidt, and J.N. Thomas. 1997. Expression augmenting sequence element (EASE) isolated from chinese hamster ovary cells. In Animal Cell Technology: from Vaccines to Genetic Medicine. M.J.T. Carrondo, B. Griffiths, and J.L.P. Moreira, editors. Kluwer Academic Publishers, Boston. 529-534.

18. Spriggs, M.K., R.J. Armitage, L. Strockbine, K.N. Clifford, B.M. Macduff, T.A. Sato, C.R. Maliszewski, and W.C. Fanslow. 1992. Recombinant human CD40 ligand stimulates B cell proliferation and immunoglobulin E secretion. J. Exp. Med. 176:1543-1550.

19. Laemmli, U.K. 1970. Cleavage of structural proteins during the assembly of the head of bacteriophage T4. Nature. 227:680-685.

20. Marcus, A.J. 1990. Eicosanoid interactions between platelets, endothelial cells, and neutrophils. Methods Enzmol. 187:585-598.

21. Colman, R.W., W.R. Figures, L.M. Scearce, A.M. Strimpler, F.X. Zhou, and A.K. Rao. 1986. Inhibition of collagen-induced platelet activation by 5 '-p-fluorosulfonylbenzoyl adenosine: evidence for an adenosine diphosphate requirement and synergistic influence of prostaglandin endoperoxides. Blood. 68:565-570.

22. Sevigny, J., F.P. Levesque, G. Grondin, and A.R. Beaudoin. 1997. Purification of the blood vessel ATP diphosphohydrolase, identification and localisation by immunological techniques. Biochim. Biophys. Acta. 1334:73-88.

23. Sevigny, J., Y.P. Cote, and A.R. Beaudoin. 1995. Purification of pancreas type-I ATP diphosphohydrolase and identification by affinity labelling with the 5'-p-fluorosulphonylbenzoyladenosine ATP analogue. Biochem. J. 312:351-356.

24. Coller, B.S. 1997. Platelet GPIIb/IIIa antagonists: the first anti-integrin receptor therapeutics. J. Clin. Invest. 99:1467-1471.

25. Hennekens, C.H., C.M. Albert, S.L. Godfried, J.M. Gaziano, and J.E. Buring. 1996. Adjunctive drug therapy of myocardial infarction-Evidence from clinical trials. N. Engl. J. Med. 335:1660-1667.

26. Moodie, F.D.L., H. Baum, P.J. Butterworth, and T.J. Peters. 1991. Purification and characterisation of bovine spleen ADPase. Eur. J. Biochem. 202: 1209-1215.

27. Beaudoin, A.R., J. Sevigny, G. Grondin, S. Daoud, and F.P. Levesque. 1997. Purification, characterization and localization of two ATPdiphosphohydrolase isoforms in bovine heart. Am. J. Physiol. 273:H673-H681.

28. Picher, M., Y.P. Côté, R. Béliveau, M. Potier, and A.R. Beaudoin. 1993. Demonstration of a novel type of ATP-diphosphohydrolase (EC 3.6.1.5) in the bovine lung. J. Biol. Chem. 268:4699-4703.

29. Holmsen, H., and C.A. Dangelmaier. 1989. Measurement of secretion of adenine nucleotides. Methods Enzymol. 169:195-205.

30. McGarrity, S.T., A.H. Stephenson, T.M. Hyers, and R.O. Webster. 1988. Inhibition of neutrophil superoxide anion generation by platelet products: role of adenine nucleotides. J. Leukocyte Biol. 44:411-421.

31. Gouttefangeas, C., I. Mansur, M. Schmid, H. Dastot, C. Gelin, G. Mahouy, L. Boumsell, and A. Bensussan. 1992. The CD39 molecule defines distinct cytotoxic subsets within alloactivated human CD8-positive cells. Eur. J. Immunol. 22:2681-2685.

32. Dombrowski, K.E., Y. Ke, L.F. Thompson, and J.A. Kapp. 1995. Antigen recognition by CTL is dependent upon ectoATPase activity. J. Immunol. 154:6227-6237.

33. Aziz, K.A., J.C. Cawley, A.T. Treweeke, and M. Zuzel. 1997. Sequential potentiation and inhibition of PMN reactivity by maximally stimulated platelets. J. Leukocyte Biol. 61:322-328.

34. Holmsen, H. 1994. Platelet secretion and energy metabolism. In Hemostasis and Thrombosis: Basic Principles and Clinical Practice. R.W. Colman, J. Hirsh, V.J. Marder, and E.W. Salzman, editors. J.B. Lippincott Co., Philadelphia. 524-545.

35. Bressler, N.M., M.J. Broekman, and A.J. Marcus. 1979. Concurrent studies of oxygen consumption and aggregation in stimulated human platelets. Blood. 53:167-178.

36. Packham, M.A., R.L. Kinlough-Rathbone, H.-J. Reimers, S. Scott, and J.F. Mustard. 1977. Mechanisms of platelet aggregation independent of adenosine diphosphate. In Prostaglandins in Hematology. M.J. Silver, J.B. Smith, and J.J. Kocsis, editors. Spectrum Publications, New York. 247-276.

37. Colman, R.F., P.K. Pal, and J.L. Wyatt. 1977. Adenosine derivatives for dehydrogenases and kinases. Methods Enzymol. 96:240-249. 